\title{
The effects of a polydextrose preload on appetite and energy intake
}

\author{
Nerys Astbury, Moira Taylor and Ian Macdonald \\ University of Nottingham, Nottingham, UK
}

Polydextrose is a polysaccharide composed of randomly-cross-linked glucose molecules, synthesised by the polymerisation of glucose. It has been reported that polydextrose can enhance satiety and suppress subsequent energy intake at a test meal ${ }^{(1)}$.

The present single-blind randomised cross-over study has investigated the effects of polydextrose on subjective appetite and subsequent energy intake. On two separate occasions fourteen male subjects (age 25.3 (SD 7.7) years, BMI 23.0 (SD 1.7) kg/m²) consumed a standardized breakfast at home, arrived at the laboratory at approximately 11.00 hours and were provided with a liquid preload. Preloads provided $1047 \mathrm{~kJ}(250 \mathrm{kcal})$ as a chocolate-flavoured milk shake $(400 \mathrm{ml})$ with $25 \mathrm{~g}$ polydextrose $(\mathrm{P}$ trial) or without polydextrose (energy replaced by an additional $6.25 \mathrm{~g}$ maltodextrin; $\mathrm{C}$ trial). Subjective appetite ratings were collected at 30 min intervals after the preload using visual analogue scales (VAS), and after $90 \mathrm{~min}$ subjects were provided with a pasta-based test meal to consume ad libitum. Subjects remained in the laboratory for a further $60 \mathrm{~min}$, completing VAS at 0,30 and $60 \mathrm{~min}$ after the lunch test meal was voluntarily terminated. Subjects were then free to leave the laboratory, although they were provided with a food diary in which to record all foods and drinks consumed during the remainder of the test day.

Energy intake at the test meal was lower in the $\mathrm{P}$ trial compared with the $\mathrm{C}$ trial (4819 (SD 590) kJ (1151 (SD 141) kcal) v. 5556 (SD $662) \mathrm{kJ}(1327$ (SD 158) kcal) in $\mathrm{P}$ and $\mathrm{C}$ trials respectively; $P<0.01$ ). Self-reported energy intake for the remainder of the day and total daily energy intake were not different between trials. Appetite ratings showed a significant effect of time $(P<0.05)$ but there were no differences between trials.

The study demonstrates that a liquid preload containing polydextrose can suppress voluntary food intake at a subsequent meal more than a preload containing an energy equivalent amount of maltodextrin. Inclusion of polydextrose in foods may contribute to regulating energy intake.

1. King NA, Craig SA, Pepper T \& Blundell JE (2005) Br J Nutr 93, 911-915. 